\title{
Estrongiloidosis pulmonar
}

\author{
Heiler Lozada y Jorge E. Daza
}

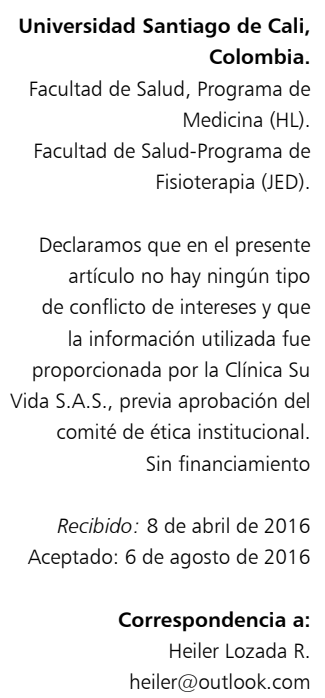

Universidad Santiago de Cali, Colombia.

Facultad de Salud, Programa de Medicina (HL)

Facultad de Salud-Programa de Fisioterapia (JED).

Declaramos que en el presente artículo no hay ningún tipo de conflicto de intereses y que la información utilizada fue proporcionada por la Clínica Su Vida S.A.S., previa aprobación del comité de ética institucional. Sin financiamiento

Recibido: 8 de abril de 2016 Aceptado: 6 de agosto de 2016

Correspondencia a: Heiler Lozada R. heiler@outlook.com

\section{Introducción}

$S$ trongyloides stercoralis es un nemátodo endémico en las regiones tropicales húmedas, incluyendo África, el sudeste de Asia y Latinoamérica. Este parásito es único en su capacidad para replicarse en el hospedero humano, permitiendo constantes ciclos de autoinfección, por lo que puede persistir durante años sin la exposición externa. El ciclo de este parásito compromete los pulmones; sin embargo, en la mayoría de casos la migración larvaria es asintomática. Presentamos un caso clínico de estrongiloidosis pulmonar, donde se pueden observar aspectos claves de los factores epidemiológicos asociados a esta condición, así como el diagnóstico y manejo que evidencian el curso de la historia natural de la enfermedad.

\section{Caso clínico}

Mujer de 45 años de edad, residente en el área urbana de Santiago de Cali (Valle del Cauca, Colombia), de estrato socioeconómico bajo, con ocupación "vendedora de dulces" en la calle. Tenía el antecedente de una gastritis crónica, una desnutrición grave, cuatro embarazos con tres hijos vivos y una cirugía de ligadura de trompas hacía 16 años. Sin antecedente de diabetes mellitus, hipertensión arterial, ni tabaquismo. Presentaba el hábito de ingerir agua no potable.

El cuadro clínico se inició tres meses antes de su ingreso hospitalario, consistente en dolor en el mesogastrio, astenia, adinamia y edema en las extremidades inferiores, evolucionando a los dos meses con episodios de diarrea fétida, emesis, y pérdida de apetito y de peso. En los últimos días presentó episodios de tos hemoptoica.
Consultó a un centro de salud periférico donde se evidenciaron larvas de $S$. stercolaris en el examen directo de deposiciones con solución salina fisiológica al 0,9\% y lugol. Se inició tratamiento médico con ivermectina durante dos días (200 $\mu \mathrm{g} / \mathrm{kg} /$ día) y albendazol (400 mg/ día). Entre los exámenes de laboratorio destacaba una albúmina de $0,5 \mathrm{~g} / \mathrm{dL}$, serología para $\mathrm{VIH}$ negativa y para HTLV I-II positiva. La TSH se encontraba normal. Siete días después la paciente se remitió a una Unidad de Cuidados Intensivos (UCI) extrainstitucional por un cuadro de dificultad respiratoria. Los diagnósticos presuntivos fueron un trombo-embolismo pulmonar (TEP), un síndrome de Löeffler o una neumonía bacteriana.

Ingresó a la UCI consciente, con signos de dificultad respiratoria, taquicárdica, afebril, con saturación arterial de oxígeno $\left(\mathrm{SaO}_{2}\right)$ por oximetría de pulso de $87 \%$, con soporte de oxígeno $\left(\mathrm{FiO}_{2} 50 \%\right)$. Al examen físico destacaba estertores finos pulmonares bibasales, abdomen sin signos de irritación peritoneal, edema grado III en extremidades inferiores y, presencia de lesiones eritematosas, pruriginosas, no descamativas en piel, predominantemente en los muslos. Los exámenes de ingreso evidenciaban leucocitos de $26.200 / \mathrm{mm}^{3}$, hemoglobina $9,1 \mathrm{~g} / \mathrm{dL}$, neutrófilos $86 \%$, eosinófilos $2 \%$, proteína $\mathrm{C}$ reactiva (PCR) $18 \mathrm{mg} /$ $\mathrm{dL}$, electrolitos y creatinina dentro de rangos normales, hipoxemia grave sin trastorno ácido-base. La radiografía de tórax mostró la presencia de infiltrados mixtos de predominio alveolar de distribución difusa (Figura 1A).

La paciente evolucionó con dificultad respiratoria progresiva, por lo que requirió finalmente ventilación mecánica invasora, sin necesidad de parámetros ventilatorios altos. Además requirió soporte vasoactivo con norepinefrina por una hipotensión arterial persistente. En su evolución clínica presentó secreciones respiratorias hemáticas constantes con descenso significativo 
de la hemoglobina, por lo que se requirió transfusión de glóbulos rojos. Ante la sospecha de una neumonía bacteriana se inició cobertura antibacteriana de amplio espectro con piperacilina/tazobactam. Posteriormente se informaron hemocultivos y urocultivo positivos para Escherichia coli productora de betalactamasas de espectro extendido (BLEE), por lo que se cambió tratamiento a meropenem. Ante la sospecha de una estrongiloidosis pulmonar se solicitó microscopía en fresco de una muestra de secreción orotraqueal, observándose larvas de $S$. stercoralis (Figura 2), por lo cual se administró una nueva dosis de ivermectina $(200 \mu \mathrm{g} / \mathrm{kg})$ y se continuó con albendazol oral (400 mg, dos veces al día). También se descartó una tuberculosis pulmonar con baciloscopias seriadas negativas. Se realizó una colonoscopia, cuyo informe anatomopatológico fue una colitis crónica leve inespecífica. No se realizaron pruebas inmunológicas para el diagnóstico de estrongiloidosis.

Se realizó el proceso de desvinculación progresiva del soporte ventilatorio, logrando la extubación al quinto día de ventilación mecánica invasora. La paciente completó una estancia hospitalaria de 12 días, período en el cual presentó episodios repetitivos de tos seca. En el seguimiento clínico el estudio coproscópico no evidenció parásitos intestinales, y la radiografía de tórax a los 15 días evidenció una resolución significativa del infiltrado pulmonar (Figura 1B). Completó 10 días de tratamiento antihelmíntico con albendazol. La hemoglobina de egreso fue de 9,9 g/dL.

Durante la permanencia en la institución la paciente recibió manejo de fisioterapia, donde se observó una evolución favorable de su condición cardiorrespiratoria $\mathrm{y}$ nivel de funcionalidad.

\section{Discusión}

Strongyloides stercolaris fue identificado por primera vez por el médico francés Louis Normand en julio de 1876 en el Hospital Naval de Toulon, al examinar las deposiciones de soldados que habían regresado del servicio militar en la Cochin-China, antiguo nombre con que se conocía a Vietnam ${ }^{1}$.

Strongyloides stercoralis es un parásito único que puede culminar su ciclo de vida completamente dentro del hospedero humano, replicándose y dando como resultado un ciclo de autoinfección. Después del inóculo inicial, el agente puede persistir en el organismo durante años, dependiendo del estado inmunológico del individuo ${ }^{2}$. Este parásito es un nemátodo intestinal endémico en las zonas tropicales o subtropicales, donde se estima que puede infectar entre 10 y $40 \%$ de esta población ${ }^{3}$. Se estima que en el mundo infecta aproximadamente entre $30 \mathrm{y}$ 100 millones de personas ${ }^{4,5}$. Esta parasitosis se relaciona
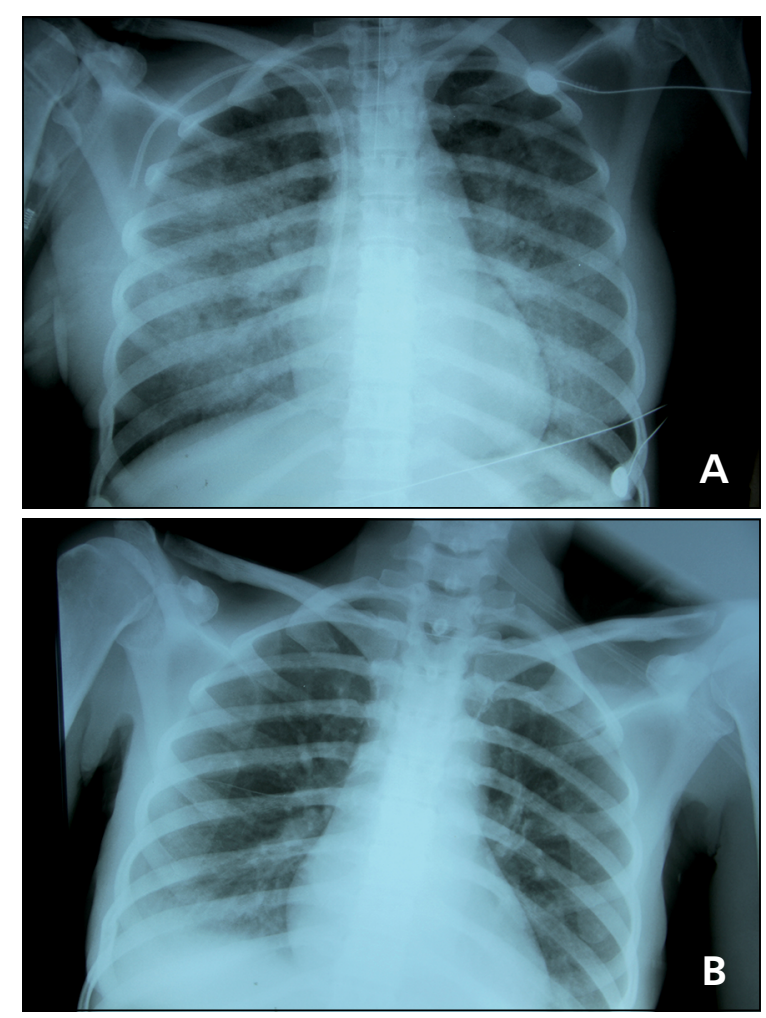

Figura 1. A. Radiografía de tórax anteroposterior que muestra infiltrados mixtos difusos de predominio alveolar en ambos campos pulmonares. B. Radiografía de tórax posterior al tratamiento farmacológico.

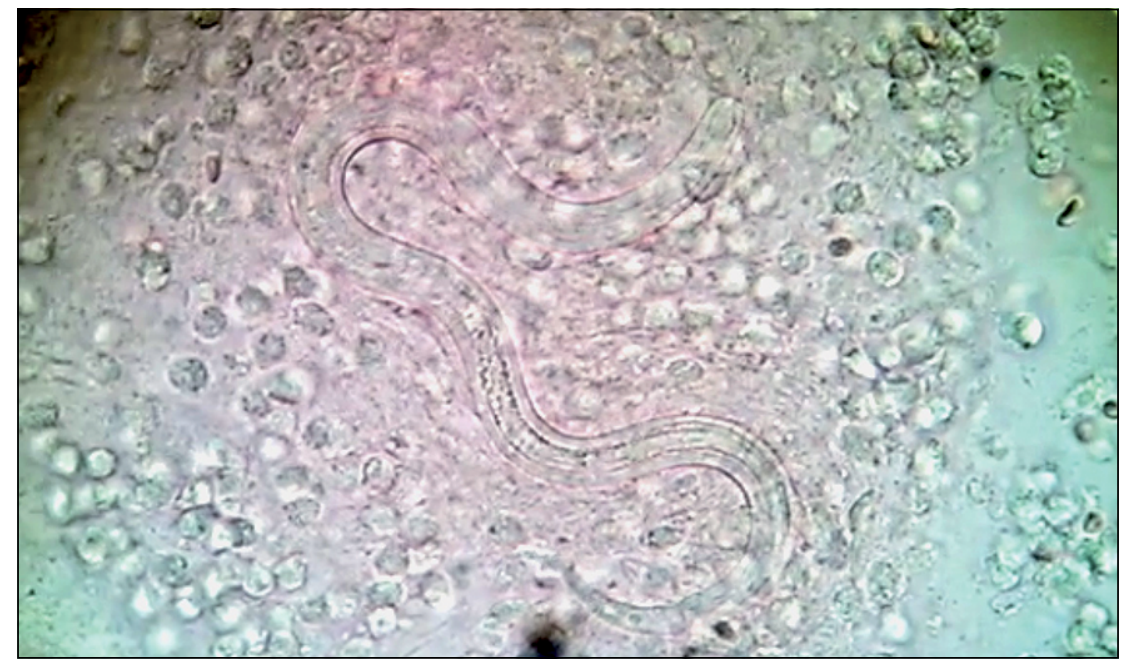

Figura 2. Microfotografía de larva filariforme de Strongyloides stercoralis en muestra de secreción traqueal.

con el bajo desarrollo socioeconómico y las deficiencias higiénicas y sanitarias de las regiones donde este helminto se considera endémico ${ }^{6}$. En Colombia, la última prevalencia estimada para esta parasitosis se encuentra entre 5 y $10 \%$; sin embargo, no se cuenta con cifras de estudios recientes, ni en la comunidad o en el ámbito hospitalario ${ }^{7}$.

El ciclo biológico de esta helmintiasis comienza con 
la penetración de las larvas de tercer estadio a través de la piel intacta, las cuales son larvas filariformes en estado infectivo. Estas traspasan el tejido celular subcutáneo $\mathrm{y}$ atravesando los capilares venosos migran hacia el corazón derecho y los pulmones. Durante este proceso experimentan una muda a larvas de cuarto estadio, que ascienden por el árbol bronquial superior hasta llegar a la tráquea, laringe y faringe, donde son deglutidas para alcanzar el intestino delgado. Allí maduran hasta adultos, y las hembras parasíticas partenogenéticas ponen sus huevos, de los que eclosionan inmediatamente las larvas rabditiformes o de primer estadio que son eliminadas con las heces. En ocasiones, pueden transformarse dentro del propio intestino a tercer estadio o larvas filariformes, posibilitando de esta manera la autoinfección al introducirse en la mucosa colónica o en la piel perianal. La transformación a larvas filariformes en el medio externo dura hasta dos semanas, quedando preparadas para penetrar en un nuevo hospedero (ciclo directo). De forma alternativa, las larvas rabditiformes pueden mudar en el medio externo hasta adultos de vida libre, alimentándose de materia orgánica. En este caso, las hembras son fecundadas y producen huevos que se desarrollan hasta larvas de tercer estadio infectivas que iniciarán un nuevo ciclo cuando penetren en un nuevo hospedero (ciclo indirecto) ${ }^{8}$.

El principal factor de riesgo en la adquisición de la infección por $S$. stercoralis es la residencia en un área endémica. Además, el hábito de bañarse en los ríos y el consumo de agua no potable ${ }^{9}$. Otros factores de riesgo es el trabajo en la agricultura y la minería. Además, la infección afecta especialmente a pacientes inmunocomprometidos con terapia inmunosupresora (particularmente corticoesteroides), con infección por VIH y HTLV-1, trasplante de órganos sólidos, neoplasias hematológicas, tumores malignos de órganos sólidos, hipogammaglobulinemia, alcoholismo crónico, desnutrición grave y diabetes mellitus ${ }^{10-13}$.

A pesar que la infección por VIH se considera un factor de riesgo, son muy pocos los casos de hiperinfección descritos en la literatura especializada; unos treinta casos descritos hasta el año 2004. Aunque hay determinadas formas de inmunosupresión que aumentan el desarrollo de formas diseminadas; no ocurre lo mismo con la inmunosupresión que ocasiona el VIH. Esto se debe a que la infección diseminada requiere del desarrollo directo de larvas rabditiformes en larvas filariformes; para lo cual probablemente es necesario un nivel adecuado de CD4. Un nivel bajo de CD4 se asocia a un aumento de larvas rabditiformes y una menor proporción de larvas filariformes ${ }^{14}$. En este caso, la paciente presentaba el antecedente de una desnutrición grave, ingesta de agua no potable e infección por virus HTLV-1, además de un nivel socioeconómico bajo. Sin embargo, no se descartó algún otro déficit inmunológico.

La infección por $S$. estercoralis tiene una amplia gama de manifestaciones clínicas, con la presencia de síntomas dermatológicos, gastrointestinales y respiratorios; sin embargo, la mayoría de pacientes pueden permanecen asintomáticos durante años. El diagnóstico se basa como en todas las parasitosis en tres pilares fundamentales: la epidemiología, la clínica y el laboratorio. Esta infección abarca cinco síndromes clínicos: infección aguda con el síndrome de Löeffler, infección intestinal crónica, autoinfección asintomática, autoinfección sintomática y el síndrome de hiperinfección o de diseminación ${ }^{11,15}$.

Dentro de estos últimos, la hiperinfección se describe como un síndrome de autoinfección acelerado, que en general, aunque no siempre, es el resultado de una alteración en el estado inmune. Además, su diagnóstico implica la presencia de signos y síntomas atribuibles a un aumento de la migración de las larvas, así como el desarrollo o exacerbación de los síntomas gastrointestinales, pulmonares, cutáneos, eosinofilia y la detección de un mayor número de larvas en las heces y/o esputo, sin olvidar que se deben recolectar muestras en diferentes días para mejorar la tasa de detección. Se ha observado en la hiperinfección la aparición de colitis, íleo paralítico recurrente asociado con enteropatía perdedora de proteínas y diarrea, dando lugar a una hipoalbuminemia y edema periférico ${ }^{11,16}$. Las manifestaciones cardiopulmonares comunes incluyen sibilancias, palpitaciones, fibrilación auricular, disnea e infrecuentemente hemoptisis masiva. En la hiperinfección por S. estercoralis, los infiltrados pulmonares son la característica más frecuente en la radiografía de tórax. Estos hallazgos incluyen nódulos miliares u opacidades reticulares que pueden ir desde una distribución lobar hasta multifocal. Estos infiltrados pueden ser ocasionados por una infección secundaria, hemorragia, neumonitis inflamatoria y formación de abscesos bacterianos. Otras manifestaciones radiográficas menos frecuentes son los cambios granulomatosos que pueden llevar a una fibrosis pulmonar $^{17}$.

La mayoría de las publicaciones relacionan el síndrome de hiperinfección con el tratamiento inmunosupresor, fundamentalmente los corticoesteroides y la coinfección con el virus HTLV-1 ${ }^{18,19}$. Del mismo modo, la paciente presentó complicaciones gastrointestinales y respiratorias, manifestadas por la presencia de larvas de $S$. stercoralis en la secreción traqueal, insuficiencia respiratoria con necesidad de soporte ventilatorio, infiltrados mixtos en la radiografía de tórax, diarrea, colitis crónica, hipoalbuminemia y edema.

La diseminación se refiere a la migración de las larvas a órganos más allá del rango del ciclo de autoinfección pulmonar, sin implicar necesariamente una mayor gravedad de la enfermedad ${ }^{11,19,20}$. La hiperinfección es a menudo complicada y relacionada con infecciones causadas por el acceso de bacterias de la flora intestinal a los sitios extraintestinales, presumiblemente a través de 
las úlceras inducidas por las larvas filariformes o llevadas en la superficie del helminto por el tracto intestinal. En los cultivos de sangre de pacientes con hiperinfección se han identificado bacterias como Escherichia coli, Klebsiella pneumoniae, Proteus mirabilis, Pseudomonas spp, Enterococcus faecalis, Staphylococcus coagulasa negativa, Streptococcus bovis y Streptococcus pneumoniae. Además, los pacientes en tratamiento inmunosupresor también pueden desarrollar infecciones sistémicas por Candida spp. por mecanismos posiblemente similares ${ }^{11,21,22}$. En nuestra paciente se documentó una bacteriemia y una infección de vías urinarias por $E$. coli.

Técnicas como la de Baermann y el cultivo en lámina de agar son engorrosas, consumen tiempo y no se dispone de ellas en muchos laboratorios clínicos. La serología es de utilidad para el diagnóstico tanto para estudios epidemiológicos como para casos individuales. Sin embargo, esta podría sobrestimar la prevalencia de infección debido a reactividad cruzada con otras infecciones por nemátodos. Recientemente, el uso de un antígeno recombinante (antígeno recombinante de Estrongyloides-NIE) aplicado a la técnica del sistema de inmunoprecipitación de luciferasa (LIPS) en lugar de la prueba de ELISA, ha mostrado una reducción prometedora de la reactividad cruzada, aunque se requieren más estudios para confirmarlo. Normalmente se presenta una lenta disminución en las pruebas serológicas, por lo que estas necesitan realizarse a los seis o doce meses después del tratamiento, lo cual puede causar una sustancial pérdida en el seguimiento de los pacientes ${ }^{23,24}$.

El tratamiento de pacientes infectados por S. estercoralis debe hacerse con el propósito de erradicar la infección. Actualmente, la ivermectina y los benzimidazoles (albendazol y tiabendazol) son los fármacos más comúnmente utilizados para el tratamiento de la estrongiloidosis. Los Centros para el Control y Prevención de Enfermedades (CDC) y la Organización Mundial de la Salud (OMS) recomiendan la ivermectina como fármaco de elección. El tiabendazol o albendazol se consideran como terapias alternativas $^{25,26}$. La terapia combinada con ivermectina y albendazol se utiliza en algunas zonas endémicas con presencia de las helmintiasis transmitidas por el suelo ${ }^{27}$.

Con respecto al uso de ivermectina, la última revisión sistemática encontró que la cura parasitológica fue mayor con este fármaco, con menor frecuencia de eventos adver- sos. En la estrongiloidosis no complicada se recomienda utilizar ivermectina con una dosis de $200 \mu \mathrm{g} / \mathrm{kg}$ vía oral diarios por uno o dos días ${ }^{28}$; como alternativa se usa albendazol $400 \mathrm{mg}$ oral, dos veces al día, por siete días o tiabendazol $25 \mathrm{mg} / \mathrm{kg}$ oral, dos veces al día, por tres días. En casos de hiperinfección o diseminación, la ivermectina se dosifica $200 \mu \mathrm{g} / \mathrm{kg} /$ día vía oral hasta que el examen en deposiciones o en esputo permanezca negativo por dos semanas $^{19,25}$, recomendación que fue aplicada en el manejo médico de la paciente. Por otro lado, se ha descrito la aplicación de ivermectina subcutánea en pacientes con estrongiloidosis grave, con resultados exitosos ${ }^{29}$.

Finalmente, el pronóstico de esta enfermedad varía de acuerdo a la presentación de la infección, estimándose una letalidad de $15 \%$ en la hiperinfección ${ }^{30}$ y aumentando significativamente a $85-100 \%$ en la estrongiloidosis diseminada ${ }^{19}$.

En conclusión, la identificación y tratamiento oportuno del síndrome de hiperinfección es de vital importancia, dada las características clínicas que presenta y la mortalidad consecuente a la que puede llevar cuando progresa a una infección diseminada. Es por ello, que el personal de salud debe conocer la presentación clínica de esta parasitosis y los factores epidemiológicos relacionados que contribuyan a un diagnóstico temprano.

Agradecimientos. A la Clínica Su Vida S.A.S. por facilitar el acceso a los documentos de la historia clínica necesarios para este caso clínico.

\section{Resumen}

La estrongiloidosis es una infección causada por el parásito Strongyloides stercoralis, la cual puede cursar con una alta morbi-mortalidad en pacientes inmunocomprometidos, con desnutrición grave y coinfección con el virus HTLV-1. Se puede desarrollar una hiperinfección, dado que el parásito tiene el potencial de producir una autoinfección interna. Se presenta un caso de infección pulmonar por S. stercoralis que progresó a una falla respiratoria y requirió soporte ventilatorio y hemodinámico en una unidad de cuidados intensivos, suministrándole el tratamiento estándar combinado de ivermectina y albendazol con una respuesta satisfactoria.

\section{Referencias bibliográficas}

1.- Globe D. A History of Human Helminthology. CAB international, Wallingford, Reino Unido 1990: 543-70.

2.- Mokhlesi B, Shulzhenko O, Garimella P, Kuma L, Monti C. Pulmonary strongyloidiasis: the varied clinical presentations. Clin Pulm Med
2004; 11: 6-13.

3.- Schar F, Trostdorf U, Giardina F, Khieu V, Muth $\mathrm{S}$, Marti H, et al. Strongyloides stercoralis: global distribution and risk factors. PLoS Negl Trop Dis. 2013; 7: e2288.

4.- Olsen A, van Lieshout L, Marti H, Polderman T, Polman K, Steinmann P, et al. Strongyloidiasisthe most neglected of the neglected tropical diseases? Trans R Soc Trop Med Hyg 2009; 103: 967-72.

5.- Bethony J, Brooker S, Albonico M, Geiger S M, Loukas A, Diemert D, et al. Soil-transmitted helminth infections: ascariasis, trichuriasis, and hookworm. Lancet 2006; 367: 1521-32.

6.- Agrawal V, Agarwal T, Ghoshal U C. Intestinal strongyloidiasis: a diagnosis frequently missed 
in the tropics. Trans R Soc Trop Med Hyg 2009; 103: 242-6.

7.- Zapata H, Rincón A M, Botero L E, Hernández M, Gutiérrez L A. Estrongiloidiasis humana: una enfermedad olvidada, un problema vigente. Medicina UPB 2014; 33: 38-47.

8.- Ruano A L, Martín T, Pardo J, López-Abán J, Muro A. Avances en el estudio sobre la estrongiloidosis. Enf Emerg 2005; 7: 102-9.

9.- Herrera J, Marcos L, Terashima A, Álvarez H, Samalvides F, Gotuzzo E. Factors associated with Strongyloides stercoralis infection in an endemic area in Perú. Rev Gastroenterol Perú 2006; 26: 357-62.

10.- Sánchez P R, Guzmán A P, Guillen S M, Adell R I, Estruch A M, Gonzalo I N, et al. Endemic strongyloidiasis on the Spanish Mediterranean coast. QJM 2001; 94: 357-63.

11.- Keiser P, Nutman T. Strongyloides stercoralis in the immunocompromised population. Clin Microbiol Rev 2004; 17: 208-17.

12.- Porto M A, Muniz A, Oliveira Júnior J, Carvalho E M. Implicações clínicas e imunológicas da associação entre o HTLV-1 e a estrongiloidíase. Rev Soc Bras Med Trop 2002; 35: 641-9.

13.- Marques C, Zago Gomes M, Gonçalves C, Pereira F. Alcoholism and Strongyloides stercoralis: daily etanol ingestion has a positive correlation with the frequency of Strongyloides larvae in the stools. PLoS Neglect Tropical Diseases 2010; 22: e717.

14.- Villena Ruíz M A, Arboleda Sánchez J A, Del Arco-Jiménez A, Fernández-Sánchez F. Neumonía grave en paciente con infección por virus de la inmunodeficiencia humana (VIH). Enferm Infecc Microbiol Clin 2012; 30: 209-11.
15.- Marcos L A, Terashima A, DuPont H, Gotuzzo E. Strongyloides hyperinfection syndrome: an emerging global infectious disease. Trans R Soc Trop Med Hyg 2008; 102: 314-8.

16.- Yoshida H, Endo H, Tanaka S, Ishikawa A, Kondo H, Nakamura T. Recurrent paralytic ileus associated with strongyloidiasis in a patient with systemic lupus erythematosus. Mod Rheumatol 2006; 16: 44-7.

17.- Kunst H, Mack D, Kon O M, Banerjee A K, Chiodini P, Grant A, et al. Parasitic infections of the lung: a guide for the respiratory physician. Thorax 2011; 66: 528-36.

18.- Buonfrate D, Requena A, Angheben A, Muñoz J, Gobbi F, Bisoffi Z, et al. Severe strongyloidiasis: a systematic review of case reports. BMC Infect Dis 2013; 13: 78.

19.- Mejía R, Nutman T B. Screening, prevention, and treatment for hyperinfection syndrome and disseminated infections caused by Strongyloides stercoralis. Curr Opin Infect Dis 2012; 25: 45863

20.- Feely N M, Waghorn D J, Dexter T, Gallen I, Chiodini P. Strongyloides stercoralis hyperinfection: difficulties in diagnosis and treatment. Anaesthesia 2010; 65: 298-301.

21.- Altintop L, Cakar B, Hokelek M, Bektas A, Yildiz L, Karaoglanoglu M. Strongyloides stercoralis hyperinfection in a patient with rheumatoid arthritis and bronchial asthma: a case report. Ann Clin Microbiol Antimicrob 2010; 9: 27.

22.- Newberry A M, Williams D N, Stauffer W M, Boulware D R, Hendel-Paterson B R, Walker P F. Strongyloides hyperinfection presenting as acute respiratory failure and gram-negative sepsis. Chest 2005; 128: 3681-4.
23.- Requena-Ménde A, Chiodini P, Bisoffi Z, Buonfrate D, Gotuzzo E, Muñoz J. The laboratory diagnosis and follow up of strongyloidiasis: a systematic review. PLoS Negl Trop Dis 2013; 7: e2002.

24.- Norsyahida A, Riazi M, Sadjjadi S, Muhammad Hafiznur Y, Low H C, Zeehaida M, et al. Laboratory detection of strongyloidiasis: IgG-, IgG4- and IgE-ELISAs and cross-reactivity with lymphatic filariasis. Parasite Immunol 2013; 35: 174-9.

25.- Centers for Disease Control and Prevention. Strongyloides. 2013 http://www.cdc.gov/ parasites/strongyloides/health professionals/ (Acceso el 27 de marzo de 2016).

26.- The Medical Letter. Drugs for parasitic infections. The Medical Letter. 3rd Edition. New York. The Medical Letter Inc 2013; 11: 20.

27.- Crompton D. W. T. Chapter 5: Preventive chemotherapy-best practice. Preventive chemotherapy in human helminthiasis. First edition. Geneva. World Health Organization 2006: 11-32.

28.- Camacho H, Gotuzzo E, Echevarría J, White A, Terashima A, Samalvides F, et al. Ivermectin versus albendazole or thiabendazole for Strongyloides stercoralis infection. Cochrane Database of Systematic Reviews 2016; 1: 1-50.

29.- Barrett J, Broderick C, Soulsby H, Wade P, Newsholme W. Subcutaneous ivermectin use in the treatment of severe Strongyloides stercoralis infection: two case reports and a discussion of the literature. J Antimicrob Chemother 2016; 71: $220-5$

30.- Vadlamudi R, Chi D, Krishnaswamy G. Intestinal strongyloidiasis and hyperinfection syndrome. Clin Mol Allergy 2006; 30: 4-8. 